\title{
Effects of human-related disturbance on breeding success of urban and non-urban blue tits (Cyanistes caeruleus)
}

\author{
Michał Glądalski ${ }^{1}$ - Mirosława Bańbura ${ }^{2}$. \\ Adam Kaliński ${ }^{3} \cdot$ Marcin Markowski $^{1}$. \\ Joanna Skwarska ${ }^{1}$ - Jarosław Wawrzyniak ${ }^{1}$. \\ Piotr Zieliński ${ }^{4}$ - Iwona Cyżewska ${ }^{1}$ • \\ Dorota Mańkowska $^{5}$ • Jerzy Bańbura ${ }^{1}$
}

(C) The Author(s) 2016. This article is published with open access at Springerlink.com

\begin{abstract}
There is a need to study the effects of urbanization on wildlife in order to understand the ecological implications of increasing urbanization and find out how to reduce its threats to biodiversity. The blue tit evolved as a forest species and prefers deciduous and mixed forests, whereas its nesting in urban habitats is a more recent phenomenon. Our long-term study of blue tit populations has been conducted in two habitats: an urban parkland (frequently visited by people) and a deciduous forest outside of the city. Using linear mixed modeling, we revealed that a relationship of blue tit breeding success (and the number of fledglings) with thermal conditions in May differed between the urban parkland and the forest. While the relationship was positive in the forest, it was negative in the parkland. In addition, breeding success in the parkland increased with increasing number of rainy days in May. We argue that the main possible reason for such patterns is human activity in the parkland, which interferes with tit parental care, especially the regular feeding of nestlings, whereas it is evidently associated with weather conditions. Human disturbance in the forest is likely to be negligible.
\end{abstract}

Michał Glądalski

mglad@biol.uni.lodz.pl

1 Department of Experimental Zoology and Evolutionary Biology, Faculty of Biology and Environmental Protection, University of Łódź, Banacha 12/16, 90-237, Łódź, Poland

2 Museum of Natural History, Faculty of Biology and Environmental Protection, University of Łódź, Kilińskiego 101, 90-011, Łódź, Poland

3 Department of Teacher Training and Biological Diversity Studies, Faculty of Biology and Environmental Protection, University of Łódź, Banacha 1/3, 90-237, Łodź, Poland

4 Department of Ecology and Vertebrate Zoology, Faculty of Biology and Environmental Protection, University of Łódź, Banacha 12/16, 90-237, Łódź, Poland

5 Urban Greenery Management, Łódź Botanical Garden, Krzemieniecka 36/38, 94-303, Łódź, Poland 
Keywords urban landscape $\cdot$ forest passerine $\cdot$ breeding success $\cdot$ human-related disturbance

\section{Introduction}

The exponential growth of urban areas has become one of the most important environmental issues worldwide; therefore studies in urban areas should be multiscaled and investigate plausible mechanisms, preferably comparing the same species (densities and mechanisms such as reproduction) in similar habitats across different hierarchical landscape levels (Chamberlain et al. 2009; Hedblom and Söderström 2012). Urban studies have paid special attention to effects on birds. Bird behavior is heavily affected by urban development, particularly as a result of predation risk, urban features (e.g. buildings, pathways, paucity of natural food and access to urban leftovers, taxonomic composition of flora, low density of trees) and various human activities (Ortega-Álvarez and MacGregor-Fors 2011). In this context urban parks are important biodiversity hotspots in cities - a park of 10-35 ha would contain most of the bird species recorded in the city (Jokimäki 1999; Fernández-Juricic and Jokimäki 2001).

Animals in general are expected to maximize fitness by overestimating rather than underestimating risks. Overestimation costs (e.g. lost feeding opportunities) have smaller fitness consequences than underestimating the danger that potentially leads to death (Bouskila and Blumstein 1992). The impacts of nonlethal human-caused disturbance on the behavior and reproductive success of animals are often analogous to predation risk (Gill et al. 1996; Gill and Sutherland 2000; Frid and Dill 2002; Le Corre et al. 2009; Kociolek et al. 2011; Marzano and Dandy 2012). Thus, the reaction of birds to the presence of mammalian predators or humans may trigger a variety of behavioral and physiological responses. A primary behavioral reaction is elicited by the central nervous system after detecting a predator. An adrenocortical response and the release of glucocorticoids evokes a secondary behavioral response (Müller et al. 2006). Birds have been found to react to the presence of a predator or human with a behavioral response (disturbing the regularity of feeding nestlings), or with an adrenocortical response (increasing the level of stress hormones), or with both those effects at the same time (Holberton et al. 1996; Platteeuw and Henkens 1997; Silverin 1998; Fowler 1999; Romero and Remage-Healey 2000; Verhulst et al. 2001; Cockrem and Silverin 2002; Nephew et al. 2003; Clinchy et al. 2004; Jarvis 2005). In small birds, like tits, the presence of humans near the nest may provoke strong behavioral responses. A parent emits alarm call and hesitates to approach the nest, and if this disturbance lasts for a long time it may cause some nestlings die from starvation or hypothermia (Müller et al. 2006).

The blue tit (Cyanistes caeruleus) evolved as a forest species and is well adapted to conditions of deciduous and mixed forests (Cramp and Perrins 1993). It survived the last glaciations mainly in the Balkan and Iberian refugia and after the last Ice Age, it have colonized Europe from these two areas (Kvist et al. 2004). Thus the availability of urban habitats suitable for breeding blue tits is a rather more recent phenomenon (Bańbura and Bańbura 2012).

Urban ecology research could be transformed into practical applications for urban landscape management and planning and that is why there is a need to study the effects of urbanization on wildlife in order to understand the ecological implications of increasing urbanization and how to reduce its threats to biodiversity (Chamberlain et al. 2009; MacGregor-Fors 2011). The effect of urbanization can be immense, yet our understanding is still rudimentary (Chace and Walsh 2006) and therefore Chamberlain et al. (2009) note that 
further comparative research between urban and non-urban populations of birds is to be welcomed.

We studied blue tit populations in two habitats: an urban parkland (frequently visited by people) and a deciduous forest (outside of the city). We assumed that human visitors often interfere with parental activities of adult blue tits in direct proportion to visiting frequency, which should lead to a difference between an urban park and a rural forest in the way in which the weather in May (the time of the nestling stage) influences breeding success. Essentially, the warm weather should be advantageous for breeding, but in the case of the urban parkland it also drastically increases the frequency of visitors. Consequently, we expected that the nice weather (warm with low rainfall) should positively influence breeding success in the forest, but the effect should be negative in the urban parkland.

\section{Study area and methods}

This study was carried out in 2000-2013 as part of a long-term project of research on the breeding biology of hole-nesting birds occupying nestboxes near Łódź, central Poland. The study areas are located in two, $10 \mathrm{~km}$ apart, structurally contrasting habitats: an urban parkland and a deciduous forest (Glądalski et al. 2016). The parkland site $\left(51^{\circ} 45^{\prime} \mathrm{N} ; 1^{\circ} 24^{\prime} \mathrm{E}\right)$, c. 80 ha (including: the zoological garden of 16 ha and the botanical garden of 64 ha), has a highly fragmented tree cover (formed artificially) and is a major recreation and entertainment area in Łódź. The forest study site $\left(51^{\circ} 50^{\prime} \mathrm{N} ; 1^{\circ} 29^{\prime} \mathrm{E}\right)$ is c. 130 ha area in the center of a mature mixed deciduous forest (1250 ha in total), bordering on the NE part of the city of Łódź, with oaks Quercus robur and $Q$. petraea as predominating species.

The data analyzed include seasons 2000-2013 in the parkland and 2002-2013 in the forest. Both areas have been equipped with wooden nestboxes (Lambrechts et al. 2010). The diameter of the nestbox entrance hole was $29 \mathrm{~mm}$. All the nestboxes were placed on trees (usually on oaks) at a height of circa $2.5 \mathrm{~m}$. In both study areas, distances between neighbouring nestboxes were about $50 \mathrm{~m}$. Mean densities of nestboxes did not differ between the parkland $(2.3 \pm 0.052$ nestboxes/ha) and the forest $(2.2 \pm 0.03 \mathrm{n} / \mathrm{ha})$ (Student's t-test for independence samples, $t=1.90, \mathrm{df}=24, p=0.07)$. Nestboxes in both the study areas were not exposed to direct sunlight during breeding seasons. We investigated orientation of the nestboxes and it had no influence on densities of birds or breeding performance (unpublished data). From early spring on, all nestboxes were checked at least once a week to detect all breeding attempts and, subsequently, breeding characteristics of tits were collected. A total of 666 first clutches of blue tits were analyzed (Table 1). Mean lying date in the parkland was only 2 days earlier than in the forest (Glądalski et al. 2015). Mean clutch size ranged from 9.69 (2013) to 11.36 (2011) in the parkland and from 10.39 (2006) to 13.03 (2003) in the forest (Glądalski et al. 2015). The breeding density of blue tits did not differ between the two sites (Student's t-test for paired samples, $t=1.57, \mathrm{df}=11, p=0.16$ ) (unpublished data, article in review). Breeding success refers to the proportion of eggs resulting in fledglings that left the nest (and refers to the nests from which at least one young left the nest). In this paper we focus on the site-specific and year-specific mean breeding success.

The open areas of the parkland are often used for playing games (large groups of children with teachers), physical recreation, concerts (sometimes very noisy) and other entertainment activities. In addition, May is the main time of the year when different building works, earthworks and maintenance of the park area are conducted. Their intensity is usually 


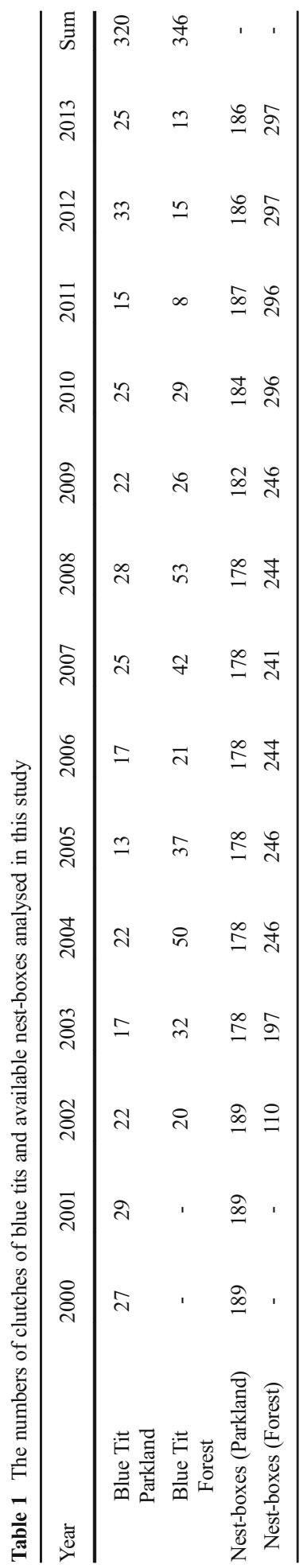


associated with the nice weather, resulting in numerous workers in the field with their loud machinery like tractors, trucks, gasoline-powered ride-on mowers and others.

The local temperatures for Łódź were obtained from TuTiempo.net climate data base (http://www.tutiempo.net/en/Climate/LODZ/124650.htm), with some gaps being filled with data from Freemeteo.com (http://freemeteo.com/default.asp?city $=\% \mathrm{C} 5 \% 82 \% \mathrm{C} 3 \% \mathrm{~B} 3 \mathrm{~d} \% \mathrm{C} 5 \%$ BA\&pid=4\&inType=1\&la=20). Following Perrins and McCleery (1989), to synthetically characterize thermal conditions of the nestling period, we calculated warmth sums for May every study year, as the sum of the maximum daily temperatures for that month.

Student's $t$-tests for paired and for independent samples were used to examine density of birds between both study sites and to compare density of nest-boxes between both study sites. We applied linear mixed models to test the relationship between breeding characteristics (breeding success and fledgling number) and the study site as factor in relation to the weather conditions in May (warmth sums and the number of rainy days as covariates). To stabilize variance and get normal distributions we arcsine transformed breeding success ( $\arcsin \sqrt{ } \mathrm{p}$ ) and square-root transformed the number of fledglings $(\sqrt{ }(n+0.5))$ before modeling (Crawley 2002). In these models we treated year and nest box ID as random factors and used RML to estimate parameters, with degrees of freedom being approximated by the Satterthwaite method (Heck et al. 2010). Following Crawley (2002), we judged the importance of particular effects in the models by analyzing their significance in an ancova style rather than using AIC-based model comparisons. Modeling was performed using the IBM SPSS Statistics 22 software (IBM SPSS Statistics 22 2013). While we used transformed data in models, non-transformed values are shown in the text and figures. Pearson's linear correlation analyses and t-tests were conducted applying STATISTICA 10 (StatSoft Inc, 2010). We considered $p \leq 0.05$ as significant.

\section{Results}

Mean number of fledglings of the blue tit ranged from 6.14 (2000) to 9.80 (2011) in the parkland and from 7.28 (2010) to 10.97 (2003) in the forest. Mean breeding success ranged from $56.97 \%$ to $89.26 \%$ at the parkland area and from $65.57 \%$ to $89.95 \%$ at the forest area. A linear mixed model showed a significant interaction between the study site factor and the sum of maximum temperatures (Table 2), suggesting that the relation between breeding success and temperature differed between the urban park and the forest. The significant estimates for the interaction in this model showed that the relation was negative in the parkland $\left(b=-0.002 \pm 0.0004(\mathrm{SE}), \mathrm{t}_{648.9}=-5.08, p<0.001\right)$ and positive in the forest $\left(\mathrm{b}=0.001 \pm 0.0003(\mathrm{SE}), \mathrm{t}_{645.8}=2.61, p=0.009\right)$ (Fig. 1). We found very similar effects for the number of fledglings, with a significant interaction between the study site factor and the sum of maximum temperatures (Table 2) - corresponding estimates of regression coefficients were negative in the park $\left(\mathrm{b}=-0.004 \pm 0.001(\mathrm{SE}), \mathrm{t}_{649.1}=-5.23, p<0.001\right)$ and positive in the forest $\left(b=0.002 \pm 0.001(\mathrm{SE}), \mathrm{t}_{646.9}=3.74, p<0.001\right)$.

We also found that an interaction that occurred between the study site and the number of rainy days in May affected breeding success of blue tit broods (Table 2), suggesting that the rainfall had a different effect on breeding success in the urban parkland and in the forest. The effect in the parkland was positive $\left(\mathrm{b}=0.014 \pm 0.01(\mathrm{SE}), \mathrm{t}_{649.2}=2.55, p=0.011\right)$, whereas in the forest it was non-significant $\left(b=-0.004 \pm 0.004(\mathrm{SE}), \mathrm{t}_{647.2}=-0.99, p=0.33\right)$. The number of fledglings in relation to the number of rainy days in May did not show analogous patterns, with the study site being the only significant effect (Table 2). 
Table 2 A summary of linear mixed model tests of the breeding success (arcsine transformed) and the number of fledglings (square-root transformed) of blue tits in relation to the study site and the warmth sum (the sum of the maximum daily temperatures for May) and the number of rainy days (in May), with year and nestbox ID being treated as random factors. Significant $P$-values in the model are in bold

\begin{tabular}{|c|c|c|c|c|c|}
\hline Y-variable & Covariate & Effect & Df & $\mathrm{F}$ & $\mathrm{p}$ \\
\hline \multirow[t]{8}{*}{ Breeding success (arcsine transformed) } & \multirow[t]{4}{*}{ Warmth sum } & Intercept & $1 ; 649.1$ & 100.0 & $<0.001$ \\
\hline & & Site & $1 ; 649.1$ & 23.9 & $<0.001$ \\
\hline & & Warmth sum & $1 ; 648.9$ & 2.3 & 0.14 \\
\hline & & Site*Warmth sum & $1 ; 648.9$ & 25.8 & $<0.001$ \\
\hline & \multirow[t]{4}{*}{$\mathrm{N}$ rainy days } & Intercept & $1 ; 648.2$ & 598.7 & $<0.001$ \\
\hline & & Site & $1 ; 648.2$ & 8.7 & 0.003 \\
\hline & & $\mathrm{N}$ rainy days & $1 ; 649.2$ & 1.4 & 0.244 \\
\hline & & Site $* N$ rainy days & $1 ; 649.2$ & 6.5 & 0.011 \\
\hline \multirow[t]{8}{*}{$\mathrm{N}$ fledglings (square-root transformed) } & \multirow[t]{4}{*}{ Warmth sum } & Intercept & $1 ; 649.3$ & 172.7 & $<0.001$ \\
\hline & & Site & $1 ; 649.3$ & 23.4 & $<0.001$ \\
\hline & & Warmth sum & $1 ; 649.1$ & 0.01 & 0.93 \\
\hline & & Site*Warmth sum & $1 ; 649.1$ & 27.4 & $<0.001$ \\
\hline & \multirow[t]{4}{*}{$\mathrm{N}$ rainy days } & Intercept & $1 ; 648.6$ & 1484.4 & $<0.001$ \\
\hline & & Site & $1 ; 648.6$ & 7.9 & 0.005 \\
\hline & & $\mathrm{N}$ rainy days & $1 ; 649.3$ & 0.3 & 0.57 \\
\hline & & Site $* N$ rainy days & $1 ; 649.3$ & 3.1 & 0.08 \\
\hline
\end{tabular}

We assess that in 2008-2013 the average number of visitors (ticket sales from the botanical garden and the zoological garden) to our parkland study site in May as the main period of the nestling stage of blue tits is about 75,000 or 938 persons/ha/month, with a clear tendency for the number of visitors to increase at the time of warm and sunny weather. The analogous average number of people passing throughout the forest study site (according to estimations made by the Forest Service) is assessed at about 1500 or 11.5 persons/ha/month. The total length of pathways per hectare is 4.5 times greater in the parkland than in the forest (for the parkland $-228.8 \mathrm{~m} / \mathrm{ha}$ and for the forest $-51.4 \mathrm{~m} / \mathrm{ha}$ ), and a mesh of paths is much more dense in the parkland. Visitor numbers (2008-2013) in the parkland area were negatively correlated with days with rain in May, $r=-0.91, n=6, p=0.01$, and tended to be related to warmth sums of May, $r=0.8, n=6, p=0.054$.

\section{Discussion}

Our predictions on an inter-habitat difference in the relationship between the May weather and blue tit breeding success were supported. There indeed was a significant interaction between the warmth sum and the study site which was affecting breeding success, with a negative effect in the urban parkland and a positive effect in the rural forest. Lower breeding success in years with warmer May in the parkland area may be associated with great numbers of visitors, entertainment events and other types of human-caused disturbance. Human recreation behaviour can interfere with wildlife in many different ways (Young et al. 2005; Chace and Walsh 2006; Remacha and Delgado 2009; Marzano and Dandy 2012). Exposure to human visitors in birds may disturb the regularity of feeding nestlings by parents (Ruiz et al. 2002; Bańbura et al. 2007, 2008). 

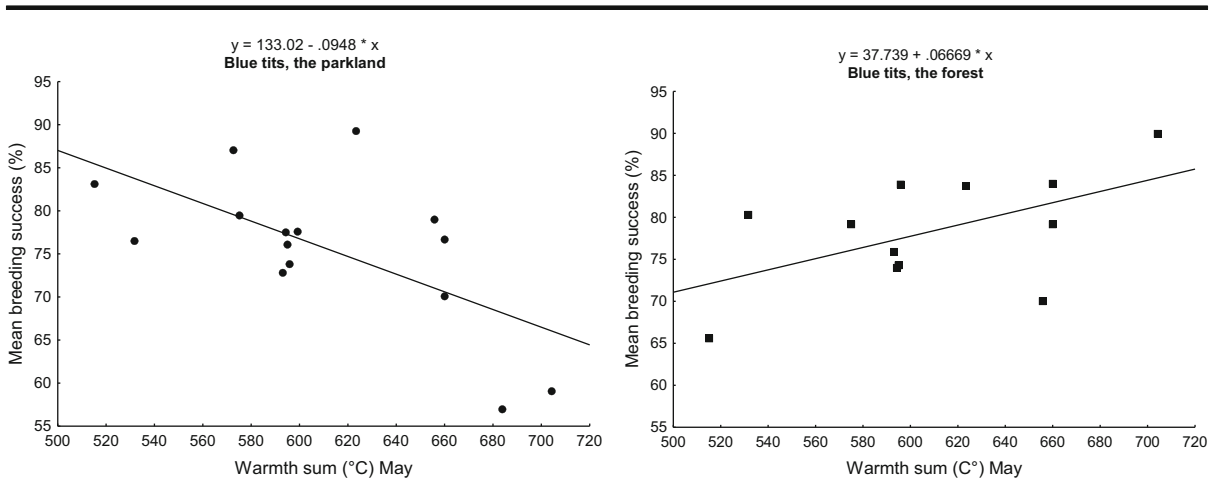

Fig. 1 Relationship between the breeding success in the parkland area (filled circles) and in the forest area (filled squares) and the sum of the daily maximum temperatures in May (seasons 2000-2013) in blue tits

Lower breeding success is also usually correlated with the number of rainy days, since rainfall often increases mortality of young tits (Zając 1995). Radford et al. (2001) showed that female great tits significantly reduced their feeding visit rate to the nest during intensive rainfall. Every reduction in the frequency of nestling feeding visits can cause long-term consequences, affecting the body weight, which is directly correlated with the probability of survival (Naef-Daenzer and Keller 1999; Radford et al. 2001; Naef-Daenzer et al. 2001). Yet we found that breeding success increased with the increasing number of rainy days. Overall, it means that lower temperatures and rain efficiently dissuade people from visiting the zoo and the botanic garden. Probably the absence of visitors facilitate foraging, perhaps except the days with very heavy rains.

Studying previously our population-habitat system, Bańbura et al. (2013) examined the heterophil-to-lymphocyte ratio $(\mathrm{H} / \mathrm{L})$ in blue tits at both study sites and found that nestlings had on average higher level of that stress indicator in the urban parkland habitat than in the forest habitat. The $\mathrm{H} / \mathrm{L}$ is considered as a reliable indicator of chronic stress reaction in birds (Gross and Siegel 1983; Ots et al. 1998; Moreno et al. 2002; Davis et al. 2008). Ruiz et al. (2002) studied the rufous-collared sparrow (Zonotrichia capensis) and after two weeks of captivity rural birds developed blood characteristics that resembled those of urban birds. These indices reveal typical primary (acute), and secondary (chronic) stress characteristics in the urban birds. This effect may be partly related to the habitat fragmentation, which has been shown to increase stress and decrease nest success of some passerines (Suorsa et al. 2003; Dietz et al. 2013). These indicators were probably influenced by several factors: food abundance, which is on average regularly lower in the parkland than in the forest habitat (Marciniak et al. 2007), habitat fragmentation (being higher in the parkland) and humancaused disturbance.

Müller et al. (2006) studied effects of human presence on corticosterone levels in parent blue tits and found no adrenocortical response to this factor. Those authors suggest that birds are able to distinguish between situations that are life-threatening and situations that are not life-threatening. This may suggest that the cause of lower breeding success may at least partly be related to disturbances preventing access to the nest.

There is also a possibility of competition between blue tits and great tits. It is possible that great tits are more active during sunny weather, which may cause more cautious behaviour of blue tits (Dhondt 1987, 2010). But densities of both tits at our parkland area are rather low and, therefore, both effects are probably negligible (unpublished data). Considering intraspecific 
competition, it was shown to be more intense in great tits than in blue tits during the breeding season (Dhondt 1977, 2010).

It is important to emphasize that there may be other unmeasured differences between both study areas and therefore present results have their limitations. Diversity in food resources may be important, e.g. it is probable that urban birds are exploiting different types of prey than forest birds. Additionally spatial variation in predator activity and proximity may have direct and indirect effects on urban passerine distributions and breeding success (Bonnington et al. 2015). There may be also differences in the adjacent habitats or small scale differences between both study areas (Hedblom and Söderström 2012).

It is still worth pointing out that the human-induced reduction in the breeding success of blue tits we found in our study is not so heavy as to seriously limit their overall demographic balance, especially when good conditions for wintering in urban parks are taken into account (Bańbura and Bańbura 2012). Moreover, cavity-nesters may also benefit from the large numbers of nest boxes in urban parks (Jokimäki 1999). Urban parks are valuable because of the preservation of the environment similar to forest in urban areas, despite the fact that the birds are not able to use their full reproductive potential. From the point of view of the full reproductive potential, it could be suggested that in large urban parklands some especially valuable areas should have restricted access for visitors.

Our data support the hypothesis that human activity could interfere breeding success of blue tit in the breeding season. But it is important to emphasize that our results are only descriptive and future experimental approach is to be welcomed.

Acknowledgments All procedures were approved by the Local Ethical Committee and the State Office for Environment Protection. The study was funded by a grant from the Polish Ministry of Science and Higher Education No. N N304 045136 and University of Łódź (No. 506/1145). We thank A. Jaksa, J. KrzemińskaFreda, R. Topola, J. Białek and D. Wrzos for their consent to conducting research work in the areas under their administration. We are grateful to T. Kurzac for his logistic help in the Botanic Garden. We are obliged to P. Procter for linguistic consultation. We thank both reviewers and the Associate Editor for their valuable and very constructive comments.

Open Access This article is distributed under the terms of the Creative Commons Attribution 4.0 International License (http://creativecommons.org/licenses/by/4.0/), which permits unrestricted use, distribution, and reproduction in any medium, provided you give appropriate credit to the original author(s) and the source, provide a link to the Creative Commons license, and indicate if changes were made.

\section{References}

Bańbura J, Bańbura M (2012) Blue tits Cyanistes caeruleus and great tits Parus major as urban habitat breeders. Inter Studies Sparrows 36:66-72

Bańbura J, Bańbura M, Kaliński A, Skwarska J, Słomczyński R, Wawrzyniak J, Zieliński P (2007) Habitat and year-to-year variation in haemoglobin concentration in nestling blue tits Cyanistes caeruleus. Comp Biochem Phys A 148:572-577

Bańbura J, Skwarska J, Kaliński A, Słomczyński R, Wawrzyniak J, Zieliński P (2008) Effect of brood size manipulation on physiological condition of nestling blue tits Cyanistes caeruleus. Acta Ornithol 43:129-138

Bańbura J, Skwarska J, Bańbura M, Glądalski M, Hołysz M, Kaliński A, Markowski M, Wawrzyniak J, Zieliński P (2013) Spatial and Temporal Variation in Heterophil-to-Lymphocyte Ratios of Nestling Passerine Birds: Comparison of Blue Tits and Great Tits. PLoS ONE, 8(9), e74226. doi - 10.1371/journal.pone.0074226. 
Bonnington C, Gaston KJ, Evans KL (2015) Ecological traps and behavioural adjustments of urban songbirds to fine-scale spatial variation in predator activity. Anim Conserv 18:529-538

Bouskila A, Blumstein DT (1992) Rules of thumb for predation hazard assessment: predictions from a dynamic model. Am Nat 139:161-176

Chace JF, Walsh JJ (2006) Urban effects on native avifauna: a review. Landsc Urban Plan 74:46-69

Chamberlain DE, Cannon AR, Toms MP, Leech DI, Hatchwell BJ, Gaston KJ (2009) Avian productivity in urban landscapes: a review and meta-analysis. Ibis 151:1-18

Clinchy M, Zanette L, Boonstra R, Wingfield JC, Smith JNM (2004) Balancing food and predator pressure induces chronic stress in songbirds. P Roy Soc B 271:2473-2479

Cockrem JF, Silverin B (2002) Sight of a predator can stimulate a corticosterone response in the great tit (Parus major). Gen Comp Endocrinol 125:248-255

Cramp S, Perrins CM (1993) The birds of the western palearctic, vol 7, Oxford University Press, Oxford

Crawley MJ (2002) Statistical computing. Wiley, Chichester

Davis AK, Maney DL, Maerz JC (2008) The use of leucocyte profiles to measure stress in vertebrates: a review for ecologists. Funct Ecol 22:760-772

Dhondt AA (1977) Interspecific competition between great and blue tit. Nature 268:521-523

Dhondt AA (1987) Polygynous blue tits and monogamous great tits - does the polygyny-threshold model hold. Am Nat 129:213-220

Dhondt AA (2010) Effects of competition on great and blue tit reproduction: intensity and importance in relation to habitat quality. J Anim Ecol 79:257-265

Dietz MS, Murdock CC, Romero LM, Ozgul A, Foufopoulos J (2013) Distance to a road is associated with reproductive success and physiological stress response in a migratory landbird. Wilson J Ornithol 125:50-61

Fernández-Juricic E, Jokimäki J (2001) A habitat island approach to conserving birds in urban landscapes: case studies from southern and Northern Europe. Biodivers Conserv 10:2023-2043

Fowler GS (1999) Behavioral and hormonal responses of magellanic penguins (Spheniscus magellanicus) to tourism and nest site visitation. Biol Conserv 90:143-149

Frid A, Dill LM (2002) Human-caused disturbance stimuli as a form of predation risk. Conserv Ecol 6:11

Gill JA, Sutherland WJ (2000) Predicting the consequences of human disturbance from behavioural decisions. In: Gosling LM, Sutherland WJ (eds) Behaviour and conservation. Cambridge University Press, Cambridge, UK, pp. 51-64

Gill JA, Sutherland WJ, Watkinson AR (1996) A method to quantify the effects of human disturbance on animal populations. J Appl Ecol 33:786-792

Glądalski M, Bańbura M, Kaliński A, Markowski M, Skwarska J, Wawrzyniak J, Zieliński P, Cyżewska I, Bańbura J (2015) Inter-annual and inter-habitat variation in breeding performance of blue tits (Cyanistes caeruleus) in Central Poland. Ornis Fennica 92:34-42

Glądalski M, Bańbura M, Kaliński A, Markowski M, Skwarska J, Wawrzyniak J, Zieliński P, Bańbura J (2016) Spatial variation in haemoglobin concentration of nestling blue tits (Cyanistes caeruleus): a long-term perspective. J Ornithol. doi:10.1007/s10336-016-1325-7

Gross WB, Siegel H (1983) Evaluation of the heterophil/lymphocyte ratio as a measure of stress in chickens. Avian Dis 34:759-761

Heck RH, Thomas SL, Tabata LN (2010) Multilevel and longitudinal modeling with IBM SPSS. Routledge, New York

Hedblom M, Söderström B (2012) Effects of urban matrix on reproductive performance of great tit (Parus major) in urban woodlands. Urban Ecosystems 15:167-180

Holberton RL, Helmuth B, Wingfield JC (1996) The corticosteronestress response in gentoo and king penguins during the nonfasting period. Condor 98:850-854

IBM SPSS Statistics 22 (2013) SPSS for Windows, Release 22.0, IBM Corporation.

StatSoft Inc (2010) STATISTICA (data analysis software system), version 10. URL: http:/www.statsoft.com.

Jarvis PJ (2005) Reactions of animals to human disturbance, with particular reference to flight initiation distance. Recent Res Developments Ecology 3:1-20

Jokimäki J (1999) Occurrence of breeding bird species in urban parks: effects of park structure and broadscalevariables. Urban Ecosystems 3:21-34

Kociolek AV, Clevenger AP, St Clair CC, Proppe DS (2011) Effects of road networks on bird populations. Conserv Biol 25:241-249

Kvist L, Viiri K, Dias PC, Rytkönen S, Orell M (2004) Glacial history and colonization of Europe by the blue tit Parus caeruleus. J Avian Biol 35:352-359

Lambrechts $\mathrm{M}$ et al. (2010) The design of artificial nestboxes for the study of secondary hole-nesting birds: a review of methodological inconsistencies and potential biases. Acta Ornithol 45:1-26

Le Corre N, Gélinaud G, Brigand L (2009) Bird disturbance on conservation sites in Brittany (France): the standpoint of geographers. J Coast Conserv 13:109-118 
MacGregor-Fors I (2011) Misconceptions or misunderstandings? On the standardization of basic terms and definitions in urban ecology. Landsc Urban Plan 100:347-349

Marciniak B, Nadolski J, Nowakowska M, Loga B, Bańbura J (2007) Habitat and annual variation in arthropod abundance affects blue tit Cyanistes caeruleus reproduction. Acta Ornithol 42:53-62

Marzano M, Dandy N (2012) Recreationist behaviour in forests and the disturbance of wild life. Biodivers Conserv 21:2967-2986

Moreno J, Merino S, Martinez J, Sanz JJ, Arriero E (2002) Heterophil/lymphocyte ratios and heat-shock protein levels and related to growth in nestling birds. Ecoscience 9:434-439

Müller C, Jenni-Eiermann S, Blondel J, Perret P, Caro SP, Lambrechts M, Jenni L (2006) Effect of human presence and handling on circulating corticosterone levels in breeding blue tits (parus caeruleus). Gen Comp Endocrinol 148:163-171

Naef-Daenzer B, Keller LK (1999) The foraging performance of great and blue tits (Parus major and $P$. caeruleus) in relation to Caterpillar development, and its consequences for nestling growth and fledging weight. J Anim Ecol 68:708-718

Naef-Daenzer B, Widmer F, Nuber M (2001) Differential post-fledging survival of great and coal tits in relation to their condition and fledging date. J Anim Ecol 70:730-738

Nephew BC, Kahn SA, Romero LM (2003) Heart rate and behavior are regulated independently of corticosterone following diverse acute stressors. Gen Comp Endocrinol 133:173-180

Ortega-Álvarez R, MacGregor-Fors I (2011) Dusting-off the file: A review of knowledge on urban ornithology in Latin America. Landsc Urban Plan 101:1-10

Ots I, Murumägi A, Hõrak P (1998) Haematological health state indices of reproducing great tits: methodology and sources of natural variation. Funct Ecol 12:700-707

Perrins CM, McCleery RH (1989) Laying dates and clutch size in the great tit. Wilson Bulletin 101:236-253

Platteeuw M, Henkens R (1997) Possible impacts of disturbance to waterbirds: individuals, carrying capacity and populations. Wildfowl 48:225-236

Radford AN, McCleery RH, Woodburn RJW, Morecroft MD (2001) Activity patterns of parent great tits Parus major feeding their young during rainfall. Bird Study 48:217-220

Remacha C, Delgado JA (2009) Spatial nest-box selection of cavity-nesting bird species in response to proximity to recreational infrastructures. Landsc Urban Plan 93:46-53

Romero M, Remage-Healey L (2000) Daily and seasonal variation in response to stress in captive starlings (Sturnus vulgaris): corticosterone. Gen Comp Endocrinol 119:52-59

Ruiz G, Rosenmann M, Novoa FF, Sabat P (2002) Hematological parameters and stress index in rufous-collared sparrows dwelling in urban environments. Condor 104:162-166

Silverin B (1998) Behavioural and hormonal responses of the pied flycatcher to environmental stressors. Anim Behav 55:1411-1420

Suorsa P, Huhta E, Nikula A, Nikinmaa M, Jantti A, Helle H, Hakkarainen H (2003) Forest management is associated with physiological stress in an old-growth forest passerine. P Roy Soc B 270:963-969

Verhulst S, Oosterbeek K, Ens BJ (2001) Experimental evidence for effects of human disturbance on foraging and parental care in oystercatchers. Biol Conserv 101:375-380

Young J, Watt A, Nowicki P, Alard D, Clitherow J, Henle K, Johnson R, Laczo E, McCracken D, Matouch S, Niemela J, Richards C (2005) Towards sustainable land use: identifying and managing the conflicts between human activities and biodiversity conservation in Europe. Biodivers Conserv 14:1641-1661

Zając T (1995) Selection on laying date in the blue tits parus caeruleus and the great tit Parus major caused by weather conditions. Acta Ornithol 30:145-151 